\title{
Erzincan'da Motorlu Taşıtlar Tarafından Atmosfere Salınan Egzoz Emisyonları ve Tahmini Miktarlarının Belirlenmesi
}

\author{
Murat ÇETIN ${ }^{1} \oplus$, Tevfik Oğuzhan ERGÜDER ${ }^{2 *}$ \\ ${ }^{1}$ Makine Mühendisliği Bölümü, Erzincan Binali Yıldırım Üniversitesi, Erzincan, Türkiye \\ ${ }^{2}$ Makine Mühendisliği Bölümü, Erzurum Teknik Üniversitesi, Erzurum, Türkiye
}

Geliş / Received: 25/10/2019, Kabul / Accepted: 25/12/2020

\begin{abstract}
Özet
Ülkemizde ulaşımda yaygın olarak içten yanmalı motorlar ile hareket eden taşıtlar kullanılmaktadır. İçten yanmalı motorlu taşıtlardan kaynaklanan zararlı egzoz gazlarının hava kirliliğinde önemli bir rolü vardır. Bu taşıtlar yaygın olarak yenilenemeyen fosil yakıtlardan üretilen benzin, motorin ve LPG gibi yakıtlarla çalıştırılmakta olup, bu yakıtların yakılması sonucunda $\mathrm{CO}, \mathrm{CO}_{2}, \mathrm{NO}_{\mathrm{x}}$ ve $\mathrm{PM}$ gibi emisyonlar atmosfere bırakılmaktadır. Erzincan il merkezinde artmakta olan motorlu taşıt sayısıyla birlikte hava kirliliği miktarı da artmaktadır. Temel olarak motorlu taşıtların atmosfere bıraktığı emisyon miktarları hesaplanırken taşıt profili ve emisyon faktörü gibi verilere gereksinim duyulmaktadır. Çalışmada kullanılan il merkezindeki taşıtlarla ilgili veriler, yapılan anket çalışmaları ve Erzincan Trafik Bölge Müdürlügü̈nden alınan bilgiler ile elde edilmiştir. Yapılan anketler ile farklı sınıflara ait 947 taşıta ulaşılmış olup, bu taşıtların üretim yılları, boyutları, Emisyon Standartları, kullandığı yakıt cinsi, kullanım amacı, segmenti gibi özellikleri belirlenmiştir. Elde edilen veriler doğrultusunda taşıtlar belirlenen sınıflara ayrıldıktan sonra COPERT 5 programı yardımıyla emisyon miktarları teorik olarak hesaplanmış, Erzincan il merkezindeki motorlu taşıt kaynaklı hava kirliliğini önlemek için öneriler sunulmuştur.
\end{abstract}

Anahtar Kelimeler: Emisyon, Erzincan, Hava Kirliliği, İçten Yanmalı Motorlar, Taşıt

\section{Investigation of Exhaust Emission Amounts Released to the Atmosphere by Motor Vehicles for Erzincan Province}

\begin{abstract}
In our country, vehicles moving with internal combustion engines are widely used in transportation. Harmful exhaust gases from internal combustion engine vehicles have an important role in air pollution. These vehicles are commonly used with fuels such as gasoline, diesel and LPG produced from non-renewable fossil fuels, and as a result of these fuels, emissions such as $\mathrm{CO}, \mathrm{CO}_{2}, \mathrm{NOx}$ and $\mathrm{PM}$ are released to the atmosphere. With the increasing number of motor vehicles in the city center of Erzincan, the amount of air pollution is also increasing. Basically, data such as vehicle profile and emission factor are needed when calculating the emission amounts released by motor vehicles into the atmosphere. The data about the vehicles in the city center used in the study were procured through survey studies and information obtained from Erzincan Traffic District Directorate. With the surveys, 947 vehicles belonging to different classes were reached and the characteristics of these vehicles such as production years, dimensions, emission standards, the type of fuel used, purpose of use and segment were determined. In line with the data obtained, after the vehicles were classified into determined classes, the emission amounts were calculated theoretically with the help of COPERT 5 program and suggestions were made to prevent air pollution caused by motor vehicles in the city center of Erzincan.
\end{abstract}

Keywords: Air Pollution, Emissions, Erzincan, Internal Combustion Engines, Vehicles 


\section{Giriş}

Dünya atmosferindeki toz, duman, su buharı, gaz şeklindeki kirleticilerin doğa ve canlılar üzerinde olumsuz etkiler edecek ve zarar verecek seviyeye erişmesine hava kirliliği denir (Çetin ve Demirci, 2016). Özellikle 19. yy'dan itibaren her geçen gün artan hava kirliliği; ormanların tahribatı, motorlu taşıt sayısındaki artış, sanayileşme gibi etmenler ile daha da önemli hale gelmiş, gün geçtikçe toplu ölümlere neden olarak tüm dünyada ortak bir soruna dönüşmüştür. Bu kirliliğe sebep olan temel faktörler; kalitesiz yakıtların yakılması, düzensiz kentleşme, sanayileşme, topografik yapı ve iklim olarak açıklanabilir. İçten yanmalı motorlar ulaşımda önemli bir yere sahip olup, fosil kökenli yakıt (benzin, LPG, dizel gibi) kullanan bu motorların da hava kirliliği üzerinde oldukça etkin bir rolü vardır. Bu yakıtların yakılmasıyla atmosfere salınan önemli kirleticiler şunlardır; Karbonmonoksit (CO), Hidrokarbonlar (HC), Azot oksitlerdir (NOx). Son teknoloji katalitik konvertörler motor normal çalışma sıcaklığında çalışırken bu gazların \%99'unu daha az zararlı olan gazlara dönüştürmektedir (Bosch, 2004).

Türkiye İstatistik Kurumu (TÜIK) Erzurum Bölge Müdürlüğü'nden alınan verilere göre; trafiğe kayıtlı araç sayısı 2018 yılı temmuz ayı sonu itibariyle 22 milyon 731 bin 759 olurken bu rakam Erzincan'da 58 bin 767 ile Türkiye il sıralamasında 63. sırada yer almıştır. Erzincan'daki bu taşıtların \%47,3'ünü otomobil, \%19'unu kamyonet, \%13,7'sini motosiklet, $\% 12,5$ 'ini traktör, $\% 3,3$ 'ünü kamyon, $\% 2,8$ 'ini minibüs, $\% 0,8$ 'ini otobüs, $\% 0,6$ 'sını ise özel amaçlı taşıtlar oluşturmaktadır. Erzincan nüfusu, 2018 y1lı verilerine göre 236.034 olarak belirlenmiş̧ir. Bu verilere göre Erzincan'da yaklaşık 4 kişiye bir motorlu taşıt, 8 kişiye bir otomobil düşmektedir (TÜIK, 2019).
Motorlu taşıtlardan kaynaklanan egzoz emisyon miktarının hesabı yapılırken, emisyon faktörü ve taşıt profil bilgisine gereksinim duyulmaktadır. Bu çalışmada Erzincan il merkezindeki motorlu taşıtların profil bilgileri ilde yapılan anket ile belirlenmiştir. Farklı marka ve model araçlar baz alınarak toplam 1000 adet taşıı ulaşmak amaçlanmış olup, toplam 947 taşıta ait anket değerleri kullanılarak çalışma tamamlanmıştır.

Anketler ile ulaşılan taşıtlar kullanım amaçları, segmentleri, üretim yılları, yakıt türü gibi niteliklerine göre sınıflandırılmıştır. Hesaplamalarda kullanılmak üzere ulaşılan taşıtların yıllık, aylık ve günlük olarak ortalama kat ettikleri mesafeleri, ortalama hızları ve ortalama yakıt tüketimleri belirlenmiştir. Toplam taşıt sayısına göre, her bir taşıt segmenti için CORINAIR ve Euro emisyon standartları baz alınarak egzoz emisyon faktörleri taşıt hızı, aldığı yol miktarı, yakıt tüketim miktarları COPERT 5 programı yardımıla teorik olarak hesaplanmıştır (Ergüder, 2019).

\section{Materyal ve Metot}

Motorlu taşıtlar tarafindan atmosfere salınan emisyonlar; soğuk emisyonlar, sıcak emisyonlar ve buharlaşma olmak üzere üç farklı sınıfta hesaplanmıştır. Soğuk emisyonlar motorun çalışma sıcaklığına ulaşıncaya kadar atmosfere salınan emisyonlar iken, sıcak emisyonlar ise motor sıcaklığı çalışma sıcaklığına ulaştıktan sonra atmosfere salınan emisyonlardır. Çalışmada CORINAIR metodolojisi kullanilarak COPERT 5 programı yardımıyla sadece egzoz emisyon hesabı yapılmamış olup, yakıtın yakıt deposu, motor ve yakıt sistemlerinden buharlaşması sonucu oluşan emisyonlar da dikkate alınarak hesaplanmıştır (Ahlvik vd., 1997). 


$$
\begin{aligned}
& \mathrm{E}_{\text {Soğuk }}=\beta \times \mathrm{N} \mathrm{x} \mathrm{f}_{\text {sicak }} \times\left(\mathrm{f}_{\text {soğuk }} / \mathrm{f}_{\text {sicak }}-1\right) \\
& \mathrm{E}_{\text {Sicak }_{\mathrm{k}, \mathrm{s}, \mathrm{a}}}=\mathrm{N}_{\mathrm{k}, \mathrm{s}, \mathrm{a}} \times \mathrm{M}_{\mathrm{s}, \mathrm{a}} \times \mathrm{f}_{\text {sicak,ylllık,k,s,a }} \\
& \mathrm{E}_{\text {Buhar }_{\mathrm{s}}}=365 \times \mathrm{b}_{\mathrm{s}}\left(\mathrm{f}_{\text {buhar }}+\mathrm{X}+\mathrm{I}\right)+\mathrm{R} \\
& \mathrm{E}_{\text {top }}=\sum_{\mathrm{y}, \mathrm{s}, \mathrm{e}, \mathrm{h}} \mathrm{E}_{\text {Sicak }_{\mathrm{s}}}+\sum_{\mathrm{s}} \mathrm{E}_{\text {Soğuk }_{\mathrm{s}}}+\sum_{\mathrm{s}} \mathrm{E}_{\text {Buhar }_{\mathrm{s}}}
\end{aligned}
$$

Soğuk emisyonlar Denklem 2.1, sicak emisyonlar Denklem 2.2 ile, yakıt deposu, motor ve yakıt sistemlerinden buharlaşması sonucu oluşan emisyonlar ise Denklem 2.3 ile hesaplanmış olup, toplam emisyon miktarı Denklem 2.4 ile elde edilmiştir. Burada;

$\mathrm{E}_{\text {top }}$ : Hesaplanan toplam emisyon miktarı

ESıcak: Motorun çalışma sicaklığına ulaştıktan sonraki çevreye bıraktığı emisyonlar

ESoğuk: Motorun çalışma sıcaklığına ulaşmadan önceki çevreye bıraktığı emisyonlar

EBuhar: Yakıtın egzoz dışındaki (yakıt deposu vb.) buharlaşmasından kaynaklanan emisyonlar
$\mathrm{N}$ : Taşıt sayısı
M: Y1llik ortalama mesafe
y: Yakıt tipi (benzin, dizel, LPG vb.)
s: Taşıt sınıfı
e: Euro sinifları
h: Taşıtların ortalama süratleri
k: Kirletici emisyonlar $\left(\mathrm{HC}, \mathrm{CO}, \mathrm{NO}_{\mathrm{x}}\right.$ ve $\left.\mathrm{PM}\right)$
a: Yol cinsi (şehir içi, şehir dışı, otoban)
f: Emisyon faktörü

$\beta$ : Taşıt sınıfına göre motor sıcaklığının çalışma sıcaklığına gelinceye kadar aldığı yol b: Taşıt sınıfları içerisindeki benzinli taşıt sayis1

$\mathrm{X}$ : Karbüratör benzinli taşıtların ortalama sıcak ve 1sınma emisyon faktörü

I: Yakıt enjeksiyonlu benzinli araçların ortalama sıcak ve isınma emisyon faktörü

R: Sıcak ve 1sınma çalışma kayıplarını göstermektedir (Ahlvik vd., 1997; Sert, 2008).

\section{Bulgular}

Hesaplamalar için kullanılacak olan taşıt park1 yapılan anketler sonucu ulaşılan veriler ile TÜİK'ten alınan Erzincan ili için motorlu taşıt sayılarına oranlanmasıyla oluşturularak Tablo 1'de verilmiştir. Bu değerler COPERT 5 programına girilerek 2. bölümde yer alan yöntem ile egzoz emisyon hesaplamaları yapılmıştır.

Tablo 1. Motorlu taşıtlar hakkında emisyon hesabı için gerekli değerler

\begin{tabular}{ccccc}
\hline Taşıt Türü & $\begin{array}{c}\text { Anket } \\
\text { Sayısı }\end{array}$ & $\begin{array}{c}\text { Hesaplanan } \\
\text { Sayı }\end{array}$ & $\begin{array}{c}\text { Yıllık Ort. Mesafe } \\
\mathbf{( k m )}\end{array}$ & $\begin{array}{c}\text { Ort. Sürat } \\
(\mathbf{k m} / \mathbf{h})\end{array}$ \\
\hline Motosiklet & $\mathbf{5 1}$ & $\mathbf{7 . 4 4 5}$ & $\mathbf{3 . 4 4 0 , 0 0}$ & $\mathbf{4 7 , 1 4}$ \\
\hline Otomobil & $\mathbf{7 3 6}$ & $\mathbf{2 5 . 4 8 9}$ & $\mathbf{1 0 . 8 9 8 , 1 4}$ & $\mathbf{5 6 , 0 2}$ \\
\hline Benzin & 196 & 9.443 & $10.265,86$ & 57,13 \\
\hline Dizel & 295 & 8.388 & $11.955,92$ & 55,02 \\
\hline LPG & 245 & 10.313 & $10.439,73$ & 56,11 \\
\hline Hafif Ticari & $\mathbf{7 8}$ & $\mathbf{1 0 . 8 9 2}$ & $\mathbf{1 8 . 1 1 3 , 8 5}$ & $\mathbf{5 3 , 2 7}$ \\
\hline Dizel & 78 & 10.892 & $18.113,85$ & 53,27 \\
\hline Otobüs & $\mathbf{8 2}$ & $\mathbf{1 3 7}$ & $\mathbf{8 1 . 9 3 6 , 5 9}$ & $\mathbf{3 0 , 7 3}$ \\
\hline Dizel & 82 & 137 & $81.936,59$ & 30,73 \\
\hline GENEL TOPLAM & $\mathbf{9 4 7}$ & $\mathbf{4 3 . 9 6 3}$ & $\mathbf{1 7 . 2 4 1 , 9 7}$ & $\mathbf{5 3 , 1 2}$ \\
\hline
\end{tabular}


Şehir merkezinde bulunan 43.963 taşıtın yaklaşık olarak \%58'ini otomobiller \%25'ini hafif ticari taşıtlar, \%17,5'ini motosikletler, $\% 0,5$ 'ini ise otobüsler oluşturmaktadır ve dağglım Şekil 1'de verilmiştir. Bu çalışmada şehir içerisinde çok fazla yer almayan tankerler, traktörler, şehirlerarası otobüsler, kamyonlar ve çekiciler hesaba katılmamıştır.

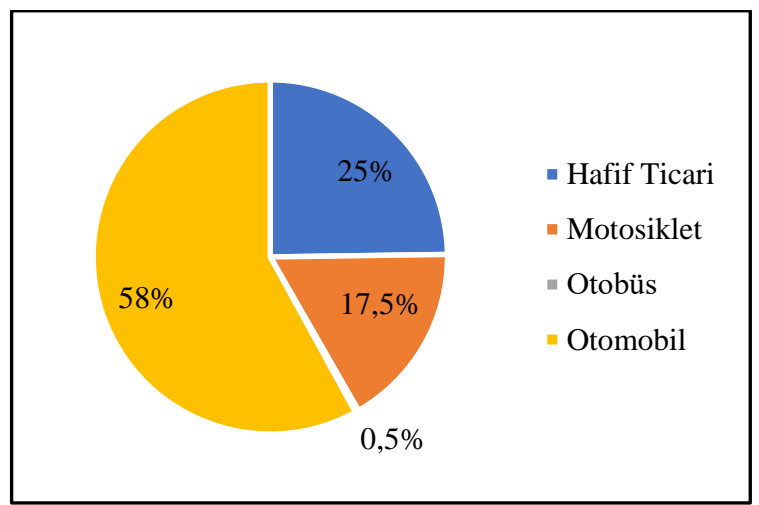

Şekil 1. Taşıt sayılarının oranları

Şehir merkezinde sirkülasyon içerisinde bulunan bu taşıtların yıllık ortalama mesafeleri anketler sonucunda yaklaş1k belirlenmiş olup, en fazla yol kat eden taşıtların \%72 oranla şehir içi taşımacılıkta kullanılan otobüsler olduğu Şekil 2'de görülmektedir. Otobüslerin ardından şehir içerisinde oldukça fazla kullanılan hafif ticari taşıtlar ise ikinci sırada yer almaktadır.

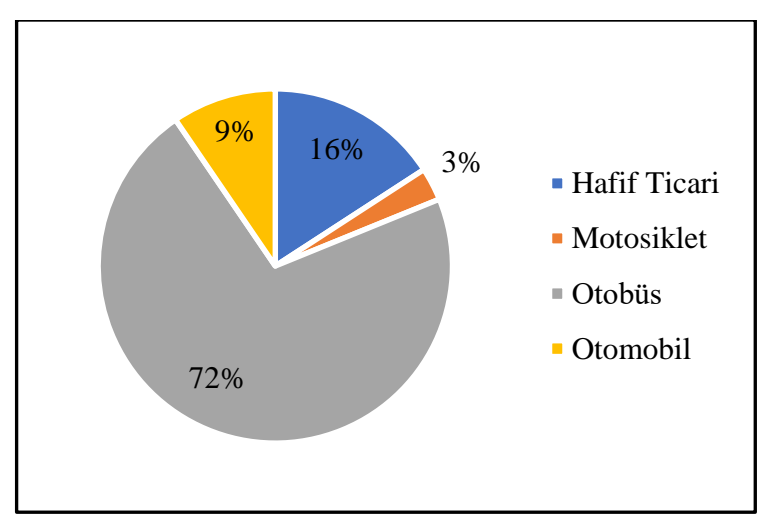

Şekil 2. Taşıtların sınıflarına göre yıllık ortalama kat ettiği mesafe oranları

$\mathrm{Bu}$ taşıtların ortalama süratleri belirlendiğinde ise en süratli olan sınıfın $\% 30$ oranla otomobiller olduğu belirlenirken, en yavaş taşıtların ise \%16 oranla otobüsler olduğu belirlenmiş olup Şekil 3'te gösterilmiştir.

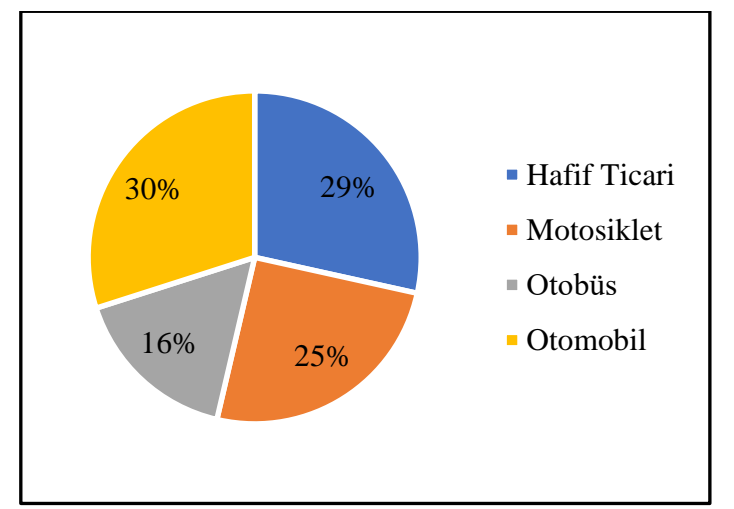

Şekil 3. Taşıtların sınıflarına göre yıllık ortalama sürat oranları

Tablo 2. Taşıt türlerine göre belirlenen toplam yakıt tüketim miktarları

\begin{tabular}{lcc}
\hline Taşıt Cinsi & Yakıt & $\begin{array}{c}\text { Tüketim } \\
\text { ton/yıl }\end{array}$ \\
\hline Motosikletler & Benzin & 335 \\
\hline $\begin{array}{l}\text { Hafif Ticari } \\
\text { Taşıtlar }\end{array}$ & Dizel & 12.217 \\
\hline Otobüsler & Dizel & 2.023 \\
\hline Binek & Benzin & 6.423 \\
Otomobil & Dizel & 4.510 \\
\hline Binek Oto Toplam & LPG & 5.956 \\
\hline GENEL TOPLAM & $\mathbf{1 6 . 8 8 9}$ \\
\hline
\end{tabular}

Hesaplamalarda kullanılan taşıt sınıflarına göre yakıt tüketim miktarları ise Tablo 2'de verilmiştir. Motosikletler toplam yaklaşık 335 ton benzin tüketimi gerçekleştirmiştir. Benzinli binek otomobiller toplam yaklaşık 6.423 ton/yıl yakıt tüketirken, dizel binek otomobiller toplam 4.510 ton/yıl, LPG'li binek otomobiller ise 5.956 ton/y1l yak1t tüketerek, binek otomobillerin toplam yakit tüketimi 16.889 ton/yıl olarak hesaplanmıştır. Yılda yaklaşık 12.217 ton yakıt tüketen hafif 
ticari taşıtlar bu tüketimi dizel olarak gerçekleştirmiş olup, otobüsler ise yılda 2.024 ton yakıt tüketmiştir. Erzincan ili için yaklaşık 6.758 ton/y1l benzin, 5.956 ton/y1l LPG ve 18.750 ton/ yıl dizel yakıt tüketimi yapılmıştır. Taşıt sınıflarına göre yakıt tüketimleri Şekil 4’te verilmiştir.

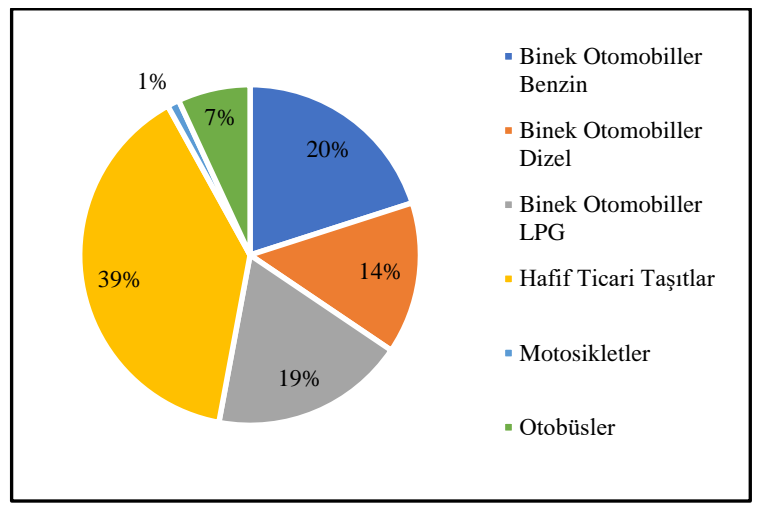

Şekil 4. Taşıt sınıflarına göre yakıt tüketimi

Tablo 3. Taşıt sınıflarına göre hesaplanan CO emisyon miktarı (ton/yıl)

\begin{tabular}{lccc}
\hline \multirow{2}{*}{$\begin{array}{l}\text { Saşıt } \\
\text { Sınıfları }\end{array}$} & \multicolumn{3}{c}{ CO emisyonu } \\
\cline { 2 - 4 } Motosiklet & 91,36 & & 91,36 \\
\hline Otomobil & $1.690,6$ & 169,0 & $1.859,7$ \\
\hline Benzin & 317,38 & 19,04 & 336,41 \\
\hline Dizel & 100,02 & 14,43 & 114,45 \\
\hline LPG & $1.273,2$ & 135,60 & $1.408,8$ \\
Hafif Ticari & 458,67 & 66,15 & 524,83 \\
\hline Otobüsler & 202,32 & & 202,32 \\
\hline TOPLAM & $\mathbf{2 . 4 4 3 , 0}$ & $\mathbf{2 3 5 , 2 1}$ & $\mathbf{2 . 6 7 8 , 2}$ \\
\hline
\end{tabular}

Erzincan şehir merkezi için COPERT 5 programı yardımıyla tüm taşıt sınıflarına ait hesaplanan sicak ve soğuk $\mathrm{CO}$ emisyon miktarları Tablo 3'te verilmiştir. Motosikletler için toplam yaklaşı yılda 91 ton/yıl, binek otomobiller için toplam yaklaşık 1.860 ton/yıl, hafif ticari taşıtlar için yaklaşık
525 ton/yıl, otobüsler için yaklaşık 202 ton/y1ldır. Binek otomobillerde CO emisyon miktarı 1.409 ton/yıl ile en fazla LPG'li taşıtlarda görülmekte olup, LPG yakıtını kullanan taşıtların sayıca fazla olmasının yanı sıra bu taşıtların daha çok düşük Euro emisyon standardına sahip eski model taşıtlardan oluşmasından kaynaklanmaktadır. Benzinli binek otomobiller gerek sayısının azlığı gerekse de daha yüksek Euro sınıfına dâhil olmaları sebebiyle yılda yaklaşık 336 ton ile ikinci sirada gelmektedir.

Dizel motorlarda oldukça fazla olan NOx emisyonlarını azaltmanın en verimli yolu yanma odasındaki sicaklığın düşük tutulmasıdır. Pratik bir yöntem olmasına rağmen, maksimum ısıl verim elde etmek için sisteme olan 1sı girişinin mümkün olan en yüksek sicaklıkta gerçekleşmesi gerektiğinden, bu metot motorun verimini de düşürmektedir (Kouremenos vd., 2001; Sher, 1998). Bu yüzden dizel yakıtı kullanan binek otomobiller sayıca az olmasının yanı sıra fakir karışımla çalışmaları 114 ton/yıl CO emisyon miktarı ile üçüncü sırada yer almaktadır. Hafif ticari taşıtların kat ettiği mesafe otomobillere göre daha fazla olmasına rağmen hem sayıca az olmaları hem de dizel yakıt kullanmalarından dolayı yaklaşık 525 ton/yıl CO emisyon miktarına sahiptir. Aynı şekilde otobüsler de yaklaşık 202 ton/yıl CO emisyon miktarına sahiptir. Erzincan şehir merkezi için toplam CO emisyon miktarı yaklaşık 2.678 ton/yıl olarak hesaplanmıştır. Taşıt sınıflarına göre CO emisyon salınım oranları Şekil 5'te verilmiştir. 


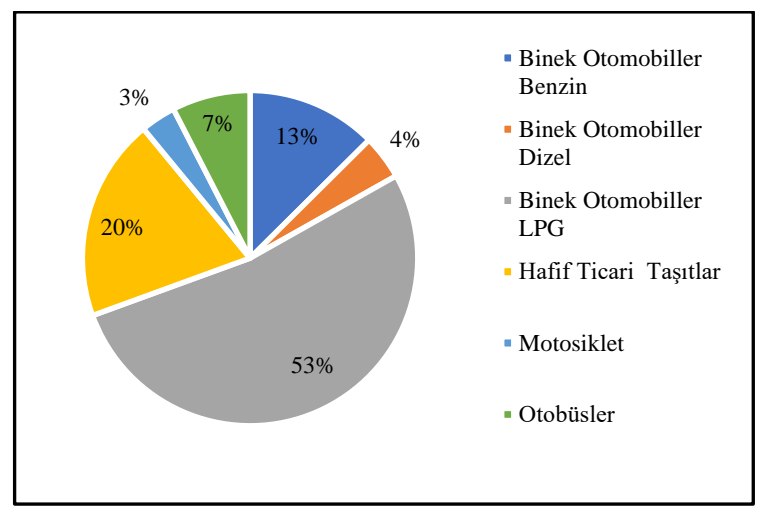

Şekil 5. Motorlu taşıtlara göre CO emisyon salınım oranı

Erzincan şehir merkezi için COPERT 5 programı yardımıyla tüm taşıt sınıflarına ait hesaplanan sicak, soğuk ve benzin deposu, açık sistem yakıt kullanan otomobillerde buharlaşmalardan kaynaklanan $\mathrm{HC}$ emisyon miktarları Tablo 4'te verilmiştir. Hidrokarbonların en önemli kaynakları yanma odası etrafındaki boşlukların sıkıştırma zamanı sırasında hava/yakıt karışımı ile dolmas1, yakıtın absorbsiyonu, yanma sonucu oluşan kalıntıların yă̆ filmi özelliği göstermesi, silindir içerisinde yanmamış yakıt bulunmasıdır (Sürmen, 1997; Yıldırım ve Gül,1997).

Zengin karışımda tam yanmanın oluşabilmesi için yeterli miktarda $\mathrm{O}_{2}$ olmadığından $\mathrm{HC}$ emisyonları artarken, fakir karışımda ise düşük alev yayılma sürati nedeniyle yakıt tam olarak yanmadan dışarı atıldığından yine $\mathrm{HC}$ emisyonları artmaktadır. $\mathrm{Bu}$ emisyonların artmasına sebep olan bir diğer neden ise motor freni ve yavaşlama sırasında motora yeterli miktarda hava giremeyeceğinden düşük sıkıştırma ve zengin karışım ile birlikte eksik yanma oluşmasıdır (Stone, 1989).

Toplam HC emisyon miktarı il merkezi için yaklaşık 458 ton/yıl olarak hesaplanmıştır. Motosikletler yılda yaklaşık 14 ton/yıl, binek otomobiller yılda yaklaşık 290 ton/y1l, hafif ticari taşıtlar yılda yaklaşık 122 ton/yıl, otobüsler ise yılda yaklaşık 32 ton/yıl HC emisyonu salınımı yapmıştır. Özellikle yanmamış yakıtın atmosfere bırakılması nedeniyle meydana gelen bu emisyon, LPG yakıtının uçuculuğunun oldukça yüksek olması sebebiyle LPG'li taşıtlar HC salınımında birinci sıradadır. Benzinde yapılan geliştirmeler ve bu sınıfa ait taşıtların Euro emisyonlarının yüksek olması sebebiyle benzinli binek otomobillerde $\mathrm{HC}$ emisyon miktarı yıllık 29 ton/yıl olarak hesaplanmıştır. Taşıt sınıflarına göre HC emisyon salınım oranları Şekil 6'da verilmiştir.

Tablo 4. Taşıt sınıflarına göre hesaplanan HC emisyon miktarı (ton/yıl)

\begin{tabular}{lcccc}
\hline \multicolumn{5}{c}{ HC Emisyonu } \\
\hline Taşıt Sınıfı & Sıcak & Soğuk & Buharlaşma & Toplam \\
\hline Motosikletler & 14,15 & & 0,30 & 14,45 \\
\hline Binek Otomobiller & 254,03 & 29,92 & 5,67 & 289,62 \\
\hline \multicolumn{1}{c}{ Benzin } & 20,85 & 2,92 & 5,67 & 29,44 \\
\hline \multicolumn{1}{c}{ Dizel } & 5,71 & 1,54 & & 7,25 \\
\hline \multicolumn{1}{c}{ LPG } & 227,47 & 25,46 & & 252,93 \\
\hline Hafif Ticari Taşıtlar & 96,15 & 26,02 & & 31,81 \\
\hline Otobüsler & 31,81 & & & $\mathbf{4 5 8 , 0 7}$ \\
\hline GENEL TOPLAM & $\mathbf{3 9 6 , 1 4}$ & $\mathbf{5 5 , 9 4}$ & $\mathbf{5 , 9 7}$ & \\
\hline
\end{tabular}




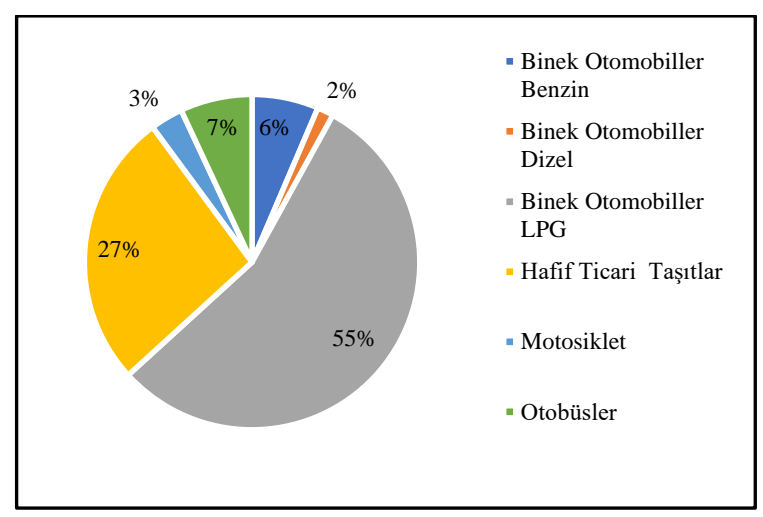

Şekil 6. Motorlu taşıtlara göre $\mathrm{HC}$ emisyon salınım oranı

Çok kirli havalarda bulunan $\mathrm{NO}_{\mathrm{x}}$ konsantrasyonları mukoza zarının tahriş olmasina sebep olabilir. Azot oksitler asit yağmurlarına neden olarak orman hasarlarına katkıda bulunur ve aynı zamanda hidrokarbonlarla kombineli şekilde hareket ederek fotokimyasal sis oluşturur. Daha çok dizel motorlarda meydana gelen bu emisyonlar, buji ile ateşlemeli motorlarda ihmal edilebilecek seviyededir (Bilgin ve Durgun, 1997; Heywood, 1988).

$\mathrm{NO}_{\mathrm{x}}$ emisyon miktarı Erzincan il merkezi için toplam yaklaşık 6.519 ton/y1l olarak hesaplanmıştır. Özellikle dizel yakıtın yakılmasıyla atmosfere birakılan bu emisyonlar yaklaşık olarak hafif ticari taşıtlarda 3.963 ton/y1l, dizel binek otomobillerde ise 992 ton/y1l olarak hesaplanmıştır. Otobüslerde ise toplam yaklaşık 848 ton/yıl olarak belirlenmiştir.

Buji ile ateşlemeli motorlarda ihmal edilebilecek düzeyde olan $\mathrm{NO}_{\mathrm{x}}$ emisyonları benzinli motosikletler için 5 ton/y1 hesaplanırken, binek otomobiller için 77 ton/yıl olarak hesaplanmıştır. Taşıt sınıflarına göre $\mathrm{NO}_{\mathrm{x}}$ emisyon miktarları Tablo 5'te, oranları ise Şekil 7'de verilmiştir.
Tablo 5. Taşıt sınıflarına göre hesaplanan $\mathrm{NO}_{\mathrm{x}}$ emisyon miktarı (ton/yıl)

\begin{tabular}{lccc}
\hline Emisyon Cinsi & \multicolumn{3}{c}{ Taşıt Sınıfları } \\
\hline NOx & Sıcak & Soğuk & Toplam \\
\hline Motosikletler & 4,58 & & 4,58 \\
\hline Benzin & 4,58 & & 4,58 \\
\hline B. Otomobil & $1.665,1$ & 38,73 & $1.703,9$ \\
\hline Benzin & 76,01 & 0,93 & 76,94 \\
\hline Dizel & 955,56 & 36,49 & 992,05 \\
\hline LPG & 633,62 & 1,31 & 634,93 \\
\hline Hafif Ticari & $3.816,7$ & 145,7 & $3.962,5$ \\
\hline Otobüsler & 848,27 & & 848,27 \\
\hline G. TOPLAM & $\mathbf{6 . 3 3 4 , 8}$ & $\mathbf{1 8 4 , 5}$ & $\mathbf{6 . 5 1 9 , 3}$ \\
\hline
\end{tabular}

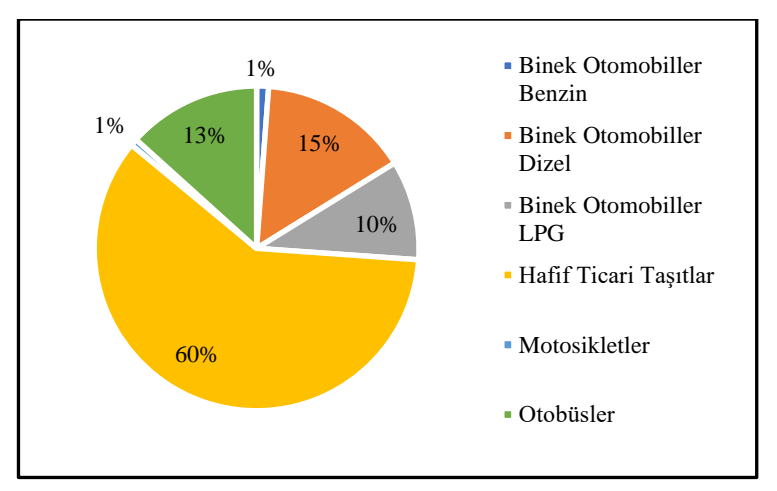

Şekil 7. Motorlu taşıtlara göre $\mathrm{NO}_{\mathrm{x}}$ emisyon salınım oranı

PM emisyonları motosikletlerde yaklaşık 1 ton/y1l, benzinli binek otomobillerde yaklaşık 3 ton/yıl olarak hesaplanırken, LPG yakıtı kullanan binek otomobillerde yaklaşık 4 ton/yıl olarak hesaplanmıştır. Dizel yakıtlı binek otomobillerde ise yaklaşık 18 ton/y1 olarak hesaplanırken, hafif ticari taşıtlarda yaklaşık 116 ton/yıl olarak hesaplanan bu emisyon otobüslerde ise yaklaşık 13 ton/yıl olarak hesaplanmıştır. Tablo 6'da taşıt sınıflarına göre PM emisyon miktarları gösterilmiştir. Şekil 8'de ise taşıt sınıflarına göre oranları verilmiştir. $\mathrm{NO}_{\mathrm{x}}$ emisyonu gibi daha çok dizel otomobillerde ortaya çıkan PM 
emisyon miktarı Erzincan il merkezi için yaklaşık 155 ton/yıl olarak hesaplanmıştır. Bu emisyonların oluşmasındaki en önemli etken silindir içerisinde yeterli hava bulunamaması sonucu yakıtın tam olarak yanmayarak egzoz gazına karışmasıdır.

Tablo 6.Taşıt sınıflarına göre hesaplanan PM emisyon miktarı (ton/y1l)

\begin{tabular}{cccc}
\hline Taşıt Sınıfları & \multicolumn{3}{c}{ PM Emisyonu } \\
\hline & Sıcak & Soğuk & Toplam \\
\hline Motosikletler & 0,57 & & 0,57 \\
\hline B.Otomobil & 22,24 & 3,40 & 25,65 \\
\hline Benzin & 3,53 & & 3,53 \\
\hline Dizel & 14,32 & 3,40 & 17,72 \\
\hline LPG & 4,40 & & 4,40 \\
\hline Hafif Ticari & 93,79 & 22,29 & 116,08 \\
\hline Dizel & 93,79 & 22,29 & 116,08 \\
\hline N1-I & 8,20 & 1,95 & 10,15 \\
\hline Otobüsler & 12,54 & & 12,54 \\
\hline TOPLAM & $\mathbf{1 2 9 , 1 5}$ & $\mathbf{2 5 , 7 0}$ & $\mathbf{1 5 4 , 8 4}$ \\
\hline
\end{tabular}

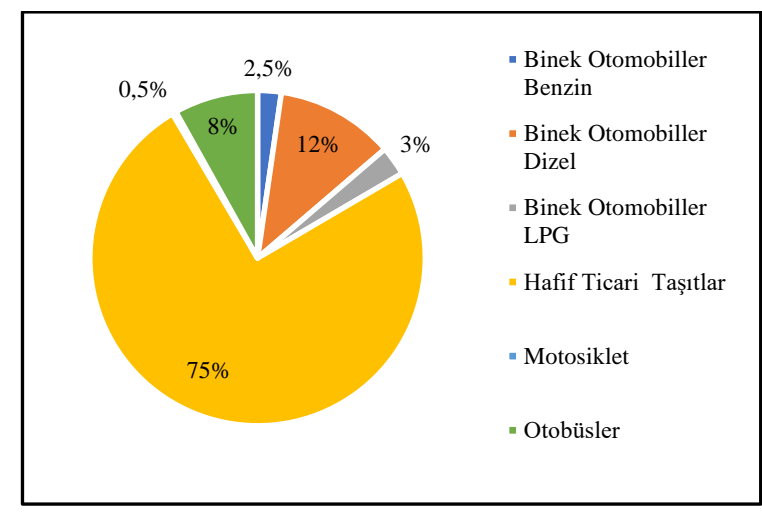

Şekil 8. Motorlu taşıtlara göre PM emisyon salınım oranı

\section{Sonuç ve Öneriler}

$\mathrm{Bu}$ çalışmada, Erzincan il merkezindeki motorlu taşıtlardan kaynaklanan hava kirliliğinin hesaplanması CORINAIR metodolojisi baz alınarak yapılmıştır. Hesaplama için gerekli olan veriler anket yardımıyla elde edilip, taşı parkı oluşturularak hava kirliliğine sebep olan taşıtlar sınıflara ayrılıp, her bir sınıfın yıllık ortalama kat ettiği mesafe, ortalama sürat, ortalama yakıt tüketimi gibi bilgiler COPERT 5 programına girilerek emisyon hesaplamaları yapılmış ve toplam emisyon miktarları Tablo 7 'de verilmiştir.

Tablo 7. Erzincan ili için hesaplanan toplam emisyon değerleri

\begin{tabular}{llcccc}
\hline Taşıt Cinsi & Yakıt Türü & CO ton/yıl & HC ton/yıl & NOx ton/yıl & PM ton/yıl \\
\cline { 2 - 6 } Motosikletler & Benzin & 91,36 & 14,45 & 4,58 & 0,57 \\
\hline Hafif Ticari Taşıt. & Dizel & 524,83 & 122,18 & $3.962,53$ & 116,08 \\
\hline Otobüsler & Dizel & 202,32 & 31,81 & 848,27 & 12,54 \\
\hline \multirow{2}{*}{ Binek Otomobil } & Benzin & 336,41 & 29,44 & 76,94 & 3,53 \\
& Dizel & 114,45 & 7,25 & 992,05 & 17,72 \\
& LPG & $1.408,88$ & 252,93 & 634,93 & 4,40 \\
\hline Binek Otomobil Toplam & $\mathbf{1 . 8 5 9 , 7 4}$ & $\mathbf{2 8 9 , 6 2}$ & $\mathbf{1 . 7 0 3 , 9 2}$ & $\mathbf{2 5 , 6 5}$ \\
\hline GENEL TOPLAM & & $\mathbf{2 . 6 7 8 , 2 5}$ & $\mathbf{4 5 8 , 0 7}$ & $\mathbf{6 . 5 1 9 , 3 1}$ & $\mathbf{1 5 4 , 8 4}$ \\
\hline
\end{tabular}


Erzincan'da motorlu taşıtlardan kaynaklı emisyonların azaltılması için;

- Toplu taşıma kullanımının yaygınlaştırılması için teşvik edici düzenlemelerin yapilması.

- Toplu taşımada kullanılan taşıtların Euro emisyon standartlarının yükseltilmesi veya CNG, hibrid, elektrik gibi alternatif yakıtla çalışan toplu taşıma araçlarının kullanılması.

- Toplu taşıma araçlarında sürekli dur-kalkın önlenmesi için durak sayılarının azaltılması veya ana caddelerde toplu taşıma araçları için ayrı bir şerit düzenlenmesi.

- Trafik işaretlerinin trafiğin akışını engellemeyecek (yeşil dalga sistemi vb.) şekilde düzenlenmesi.

- Şehirde hava kirliliğine daha az sebep olan yeni taşıtların trafikte dolaşması için vergi teşviki gibi teşviklerle halkın bu taşıtlara yönelmesinin sağlanması.

- Trafikteki araçların düzenli bakımlarının yaptırılması için gerekli kontrol ve denetimlerin arttırılması.

- Motorlu taşıt kütlesini artıracak gereksiz eşyaların araçlardan alınması.

- Şehir merkezinde özellikle trafiğin yoğun olduğu bölgede yeşil alan, park, bahçe sayısının arttırılması.

- Özel otomobil kullanımında kisitlamalar getirilmesi veya bunların doluluk oranlarının arttırılması.

- Erzincan şehir merkezi düz bir yapıya sahip olduğundan şehir içi ulaşımda bisiklet kullanımının yaygınlaştırılması gibi önlemler alınabilir.

- Tüm bu düzenlemelerin başarıya ulaşması için taşıt emisyonları ve atıkları konusunda toplumsal bilinç düzeyinin geliştirilmesi ve sürdürülebilirliğini sağlayacak eğitim faaliyetlerinin yapılması gerekmektedir.

\section{Kaynaklar}

Ahlvik, P., Eggleston, S., Gorißen, N., Hassel, D., Hickman, A.-J., Joumard, R., and Zierock, K.-H. (1997) "COPERT II Computer Programme to calculate Emissions from Road Transport Methodology and Emission Factors". European Environment Agency.

Bilgin, A. ve Durgun, O. (1997) "Taşıt Motorlarında Kirletici Oluşum Mekanizmaları ve Önlenmesi”, 5.Yanma Sempozyumu, Kirazliyayla /Bursa Türkiye.

Bosch, Robert GmbH. (2004). "GasolineEngine Management 2nd Edition”.

Çetin, M. (2010) “Türkiye'de Motorlu Taşıt Profilleri, Mevcut ve Gelecek Sera Gazı Emisyonları Potansiyeli", 11th International Combustion Symposium, Bosna Hersek.

Çetin, M., ve Demirci, O.K. (2016) “Erzincan'da Doğal Gaz Kullanımının Hava Kalitesine Etkisi”. Erzincan Üniversitesi Fen Bilimleri Enstitüsü Dergisi, (cilt 9), 08-18.

Ergüder, O. T., (2019) "Erzincan Şehir Merkezinde Motorlu Taşıt Emisyonları Kaynaklı Hava Kirliliği Düzeyinin Araştırılması", (Yüksek Lisans Tezi), Erzincan Binali Yıldırım Üniversitesi Fen Bilimleri Enstitüsü, Erzincan.

Heywood, B. J. (1988) "Internal Combustion Engine Fundamentals". McGrawHill, Newyork.

Kouremenos, D A, Hountalas, D T, Binder, K B, Raab, A. and Schnabel, M H. (2001) "Using Advanced Injection Timing and EGR to Improve DI Diesel Engine Efficiency at Acceptable No and Soot Level". Society of Automotive Engineers Inc., Warrendale, PA, SAE paper no. 2001-01-0199. 
Sert İ., (2008) "Balıkesir İlk Merkezinde Motorlu Taşıtlardan Kaynaklanan Emisyon Envanterinin Hesaplanması", (Yüksek Lisans Tezi), Balıkesir Üniversitesi Fen Bilimleri Enstitüsü, Balıkesir.

Sher E. (1998) "Handbook Of Air Pollution From Internal Combustion Engines. Pollutant Formation and Control" Academic Press, Boston, 312-315.

Stone, R. (1989) "Motor Vehicle Fuel Economy". Macmillan Educational Ltd., Houndsmills.

Sürmen, A. (1997) "Buji ile Ateşlemeli Motorlarda HC emisyonlarının Oluşumu ve Alev Geçişi Sonrası Davranımının Matematik Modeli” 5.Yanma Sempozyumu, Kirazlıyayla/Bursa, Türkiye.

TÜiK (2019) Trafiğe Kayıtlı Araç Sayısı. Erzurum Bölge Müdürlüğ̈u.

Ylldırım, M., ve Gül, Z. (1997) "Buji ile Ateşlemeli Motorlarda Segman Boşluğu Hidrokarbonlarının Çok Boyutlu Matematik Modeli”, 5.Yanma Sempozyumu, Kirazlıyayla/Bursa, Türkiye. 